\title{
\#hellomynameis at the University of Northampton
}

\author{
Cindy O'Dell and Julia Nichols, Senior Lecturers in Nursing, and Vicky Simpson,
}

formerly Adult Nursing student, University of Northampton

In August, 120 preregistration nursing students from the University of Northampton paid tribute to the \#hellomynameis campaign and the work of Dr Kate Granger. The students used their final day at the university to celebrate their achievements with a day of events, which included an awards ceremony and a summer picnic. Vicky, an Adult Nursing student from the cohort, suggested that the group could use the opportunity to honour the work of Dr Kate Granger and reflect their commitment to the philosophy of being a 'brilliant' nurse.

The \#hellomynameis campaign is reflected in the philosophy of the undergraduate nursing programme at the University of Northampton. The university has introduced a positive psychology programme called Being Brilliant, which has been threaded throughout the curriculum. The principles of this approach are simple and focus on small behaviours and ways of thinking that can have a big impact on the way students behave in their personal and professional lives. This has helped students at Northampton to develop and become more confident in demonstrating compassionate care and communication. Being Brilliant is based around six key principles: having a positive attitude; going the extra mile; bounce-backability; understanding your impact; recognition and celebration of achievement; and showing appreciation and gratitude. These principles are introduced to students at pre-enrolment and developed and reinforced across the 3 years of the curriculum, through a number of initiatives and activities. The question we ask is: 'why be an ordinary nurse when you can be a brilliant one?' One of the early Being Brilliant activities is a first-year trip to the Florence Nightingale museum, where students celebrate joining the nursing family and connect with their professional identity and heritage. At this early point, students are asked to reflect on the impact that they have on patients and how important \#hellomynameis is in building a trusting and caring therapeutic relationship.

\section{Vicky's experience}

It was during my second year of nursing training that I first heard about the \#hellomynameis campaign. I was on a placement, and when I got home I spent the evening reading about the campaign and the reasons why Dr Kate Granger developed it. I also read Kate's book, The Other Side; her dedication and commitment to her profession, right until the end, were remarkable.

When I heard that Kate had passed away, I wanted to do something to show my gratitude, empathy and compassion to her and her family. I emailed my thoughts to my tutors, and we decided to use our last day at the university to celebrate both our academic success and the work of people like Kate who have made such a positive contribution to nursing. After our 'end of programme' celebrations, as a year group we went out onto the university field and had pictures with our \#hellomynameis cards. We spent lots of time discussing how something as simple as saying 'hello, my name is' can be so meaningful to our patients.

It was not until I sat down and really thought about it that I appreciated the importance of introducing myself. As nurses working in busy environments, we often hear patients saying 'nurse' or 'excuse me', but for me there really is nothing more rewarding than hearing your name being called by a patient who needs you. It just feels much more personal and professional. It makes you feel like you're needed and valued by the person you are caring for, which inevitably makes your day. As part of my daily routine I now ensure that at the start of every shift I introduce myself to every patient that I will be looking after to let them know my name. I also find out how they would like to be known, whether it be Mrs or Mr, or a nickname of some sort-patients have nicknames too!

Communication is something we all take for granted every day, yet it is the most powerful tool to empower and respect our patients and work colleagues. Thank you Kate Granger for your inspiration.

Vicky will soon be starting work as a staff nurse at Kettering General Hospital.The nursing team at the University of Northampton have a Being Brilliant blog (bit.ly/BeingBrilliantUN) and are also on Twitter (@bebrilliantUN).You can see a video about the event here: bit.ly/Hellomynameis 